\title{
Comparison of spinal versus caudal epidural anesthesia in the management of patients undergoing ambulatory perianal surgery: Randomized, prospective study
}

\author{
Cigdem Bozkurt ${ }^{1}$, Engin Erturk², Ali Akdogan², Tugrul Kesicioglu ${ }^{3}$, Ismail Aydin ${ }^{3}$ \\ ${ }^{\prime}$ Department of Anesthesiology and Critical Care, Faculty of Medicine, Giresun University, Giresun, Turkey \\ ${ }^{2}$ Department of Anesthesiology and Critical Care, Faculty of Medicine, Karadeniz Technical University, Trabzon, Turkey \\ ${ }^{3}$ Department of General Surgery, Faculty of Medicine, Giresun University, Giresun, Turkey
}

Received: 2021-07-28.

Accepted: 2021-09-21

This work is licensed under a Creative Commons Attribution 4.0 International License

J Clin Med Kaz 2021; 18(5):76-81

Corresponding author:

Ali Akdogan.

Email: draliakdogan@yahoo.com;

ORCID: 0000-0001-7592-3844

\section{Abstract}

Objective: To compare levobupivacaine based caudal epidural anesthesia and spinal anesthesia in terms of Intraoperative hemodynamic changes and postoperative pain and patients' satisfaction in subjects undergoing perianal surgery in outpatient setting.

Material and methods: All consecutive patients who were scheduled for perianal surgery. The difference in intraoperative hemodynamic changes, sensory and motor block level, postoperative pain and patients' satisfaction was the primary outcome measure of this study.

Results: There were no significant differences between the groups in terms of mean arterial pressure and heart rate recorded. Subjects randomized to spinal anesthesia had a significant extensive motor and sensory block compared to those randomized to caudal epidural anesthesia. Visual analogue scale (VAS) scores for surgical pain at postoperative 12 hours was significantly higher in subjects receiving spinal anesthesia compared to those receiving caudal epidural anesthesia $(p=0.012)$. Time to first analgesic administration was significantly lower in subjects randomized to spinal anesthesia compared to those receiving caudal epidural anesthesia ( $\mathrm{p}=0.011)$.

Conclusion: Spinal anesthesia is associated with more extensive sensory and motor block compared to caudal epidural anesthesia in patients undergoing perianal surgery. Both techniques lead to similar hemodynamic changes. Postoperative pain control is more favorable with caudal block than the spinal anesthesia.

Key words: spinal anesthesia, perianal surgery, caudal anesthesia, analgesia

\section{Introduction}

Advances in anesthetic and surgical techniques led to an increase in outpatient surgical procedures. Performing several surgeries in outpatient setting not only reduces healthcare costs but also increases patients' satisfaction due to same day discharge after the procedure [1]. Regional intravenous anesthesia, spinal and epidural block, peripheral nerve block, topical and local anesthesia are commonly utilized in anesthesia of outpatient surgical procedures [2-5].

Perianal surgery which can be performed in outpatient setting is often performed for perianal abscess, perianal fistula, hemorrhoids, and anal fissures. General anesthesia, local anesthesia, and regional anesthesia techniques have traditionally been used in anesthesia management of patients undergoing perianal surgery [6,7]. General anesthesia has been reported to prolong hospital stay and patient discharge as a consequence of postoperative nausea and vomiting and postoperative pain compared to local and regional anesthesia $[8,9]$. On the other hand, perianal surgery with local anesthetic infiltration requires concomitant sedation which can reduce patient comfort [10-12]. Regional anesthetic techniques might be unique for use in perianal surgery since spontaneous breathing is prevented, preventative reflexes remained active, and subjects are often mobilized in early postoperative period. 
Spinal anesthesia or regional caudal block may be used for the anesthetic management of the perianal surgery. Spinal anesthesia is a simple anesthetic technique which can provide adequate muscle relaxation and analgesia with low dose local anesthetic agents $[13,14]$. However, spinal anesthesia might be insufficient, particularly in prolonged surgical procedures and additional analgesic management may be required for postoperative pain [15-17]. Caudal epidural anesthesia is safely used in anesthetic management of patients undergoing hemorrhoid surgery. Advantages of caudal epidural anesthesia over spinal anesthesia include segmental block, and limited motor block which enables early mobilization [18-20]. However, data comparing the intra-and postoperative effects of caudal epidural anesthesia and spinal anesthesia in outpatient setting is limited.

This study aimed to compare levobupivacaine based caudal epidural anesthesia and spinal anesthesia in terms of intraoperative hemodynamic changes and postoperative pain and patients' satisfaction in subjects undergoing perianal surgery in outpatient setting.

\section{Material and methods}

After the local ethic committee approval 70 patients aged $\geq 18$ years, and were American Society of Anesthesiologists (ASA) class I-II, who were scheduled for perianal surgery for perianal abscess, perianal fistula, hemorrhoids, and anal fissures were included in this study. Those with vertebral colon deformities, neurological or hematological disorders, and obese patients (body mass index $>30 \mathrm{~kg} / \mathrm{m} 2$ ) and subjects with known allergy to levobupivacaine were excluded.

Before randomization, all eligible subjects received standardized verbal and written information from a research fellow. Written informed consent was obtained from all subjects. Subjects were randomly assigned to caudal epidural anesthesia (Group C, $\mathrm{n}=35$ ) or spinal anesthesia (Group S, $\mathrm{n}=35$ ) using random allocation software. Sealed envelopes indicating patients' group were opened at operation theatre. Heart rate and peripheral oxygen saturation (SpO2) were monitored continuously; systolic, diastolic, and mean arterial pressure (MAP) were measured noninvasively at 5 min intervals during the procedure. The baseline values were recorded. All subjects received $2 \mathrm{~L} / \mathrm{min}$ of nasal oxygen was during the whole procedure. A $>30 \%$ decrease in MAP from the baseline measurement or a drop in systolic blood pressure $<90 \mathrm{mmHg}$ was defined as hypotension. 5-10 mg intravenous ephedrine was administered in case of Intraoperative hypotension. Heart rate $<50$ beats/min was defined as bradycardia. $0.5 \mathrm{mg}$ intravenous atropine was administered to manage intraoperative bradycardia.

All patients were received 1-2 $\mathrm{mg}$ of midazolam and 25-50 $\mu \mathrm{g}$ of fentanyl intravenously for premedication before the procedure. Spinal anaesthesia was performed at the L3-4 or L4-5 intervertebral space with the patient in the left-lateral decubitis position with a midline approach and a $25 \mathrm{G}$ (gauge) needle. After confirmation of free flow of clear cerebrospinal fluid, $2.5 \mathrm{ml}$ of $0.5 \%$ levobupivacaine $+25 \mu \mathrm{g}$ fentanyl was injected into the intrathecal space in 15 seconds. Caudal epidural anesthesia was performed at sacral hiatus with the patient in the prone position with a $18 \mathrm{G}$ (gauge) tuohy needle. $0.25 \mathrm{ml} / \mathrm{kg}$ of $0.5 \%$ levobupivacaine with $25 \mu \mathrm{g}$ fentanyl was then injected into the epidural space to achieve adequate anesthesia. Patients were then taken to supine position with the head elevated to 30 degrees. The sensorial block was measured at the midclavicular line with a pinprick test and the motor block was measured using the modified Bromage scale (0: no motor block, 1: hip blocked,
2: hip and knee blocked, and 3: hip, knee, and ankle blocked). Onset time and maximum cephalad spread of sensory block were recorded. All surgical procedures were carried out by the same surgical team.

Heart rate, MAP, motor block, and sensorial block, were recorded preoperatively and at 5 minutes intervals intraoperatively, and after completion of the surgery. Surgical pain was evaluated through a visual analogue scale (VAS) score ( 0 indicating no pain and 10 indicating the worst pain experienced ever). In postoperative period, subjects with a VAS score of $\geq 5$ received $50 \mathrm{mg}$ intravenous tramadol, and time to first analgesic administration was recorded. Surgeons' and patients' satisfaction was evaluated by a 4 points Likerts scale postoperatively (1 indicating low satisfaction, 2 indicating moderate satisfaction, 3 indicating good satisfaction, and 4 indicating perfect satisfaction).

The difference in intraoperative hemodynamic changes, sensory and motor block level, postoperative pain and patients' satisfaction was the primary outcome measure of this study.

\section{Statistical analysis}

Statistical analyses were carried out using SPSS (Statistical Package for the Social Sciences) for Windows, version 17 (SPSS Inc. Released 2008. SPSS Statistics for Windows, Version 17.0. Chicago: SPSS Inc.). Normality of data distribution was assessed using the Shapiro-Wilk test. Continuous variables were presented as mean \pm standard deviation (mean $\pm \mathrm{SD}$ ) and categorical variables as frequency (n) and percentage (\%). The comparison of the two groups was performed with Student's t-test, Mann-Whitney U-test, $\chi 2$-test or Fisher's exact test, where appropriate. Two-sided p-value $<0.05$ was interpreted as statistically significant.

\section{Results}

Twelve patients who did not meet the inclusion criteria were excluded, and total of 58 patients were studied as caudal epidural anesthesia $(n=28)$ or spinal anesthesia $(n=30)$. The two groups were similar with respect to age $(\mathrm{p}=0.183)$, gender $(\mathrm{p}=0.085)$, body mass index $(\mathrm{p}=0.137)$, operation time $(\mathrm{p}=0.59)$ and ASA risk score $(\mathrm{p}=0.369)$. Onset time of sensory block in Group S (4.6 \pm 3.8$)$ was faster than Group C $(13.5 \pm 5.4)(\mathrm{p}=0.017)$ (Table 1).

Table 1
\begin{tabular}{|l|l|l|l|}
\multicolumn{2}{l}{ Patients' General Characteristics and } \\
\hline & Group C (n=28) & Group S (n=30) & P - value \\
\hline Age (years) & $46 \pm 12$ & $41 \pm 14$ & $\mathrm{p}=0.183$ \\
\hline $\begin{array}{l}\text { Gender(male/ } \\
\text { female) }\end{array}$ & $21 / 7$ & $20 / 10$ & $\mathrm{p}=0.085$ \\
\hline BMI (kg/m2) & $27.63 \pm 3.76$ & $25.92 \pm 3.47$ & $\mathrm{p}=0.137$ \\
\hline $\begin{array}{l}\text { ASA risk score } \\
\text { (n) I/II }\end{array}$ & $17 / 11$ & $19 / 11$ & $\mathrm{p}=0.369$ \\
\hline $\begin{array}{l}\text { Operation time } \\
\text { (min) }\end{array}$ & $26.94 \pm 15.24$ & $29.63 \pm 16.69$ & $\mathrm{p}=0.59$ \\
\hline $\begin{array}{l}\text { Onset time of } \\
\text { sensory block }\end{array}$ & $13.5 \pm 5.4$ & $4.6 \pm 3.8$ & $\mathrm{p}=0.017^{*}$ \\
\hline
\end{tabular}

${ }^{*} \mathrm{p}<0.05$ : Onset time of sensory block in Group S was faster than Group C

There were no significant differences between the groups in terms of MAP and heart rate recorded pre-intra-and postoperatively (Table 2). Significant differences were observed between the groups in terms of motor block. Intense motor block was seen in the spinal anesthesia group, whereas no motor 
Mean arterial pressure and heart rate of the groups (Mean \pm SD)

\begin{tabular}{|l|l|l|l|}
\hline & Group C (n=28) & Group S (n=30) & $\mathrm{p}$-value \\
\hline $\begin{array}{l}\text { Mean arterial } \\
\text { pressure (mmHg) }\end{array}$ & & & \\
\hline Preoperative & $93.72 \pm 13.53$ & $101.71 \pm 17.86$ & $\mathrm{p}=0.059$ \\
\hline $\begin{array}{l}\text { Post-caudal/spinal } \\
\text { 5th min }\end{array}$ & $89.50 \pm 15.51$ & $95.71 \pm 15.84$ & $\mathrm{p}=0.248$ \\
\hline 10th min & $90.67 \pm 11.42$ & $94.88 \pm 14.60$ & $\mathrm{p}=0.488$ \\
\hline 15th min & $91.94 \pm 13.29$ & $91.13 \pm 15.59$ & $\mathrm{p}=0.813$ \\
\hline 30th min & $94.67 \pm 12.29$ & $88.75 \pm 14.59$ & $\mathrm{p}=0.747$ \\
\hline Post-surgery 1st min & $93.01 \pm 0.29$ & $91.05 \pm 17.50$ & $\mathrm{p}=0.388$ \\
\hline Postoperatif 15th min & $89.45 \pm 11.27$ & $87.57 \pm 12.56$ & $\mathrm{p}=0.897$ \\
\hline $\begin{array}{l}\text { Heart rate (beats/ } \\
\text { min) }\end{array}$ & & & \\
\hline Preoperative & $78.17 \pm 12.53$ & $85.42 \pm 18.75$ & $\mathrm{p}=0.060$ \\
\hline $\begin{array}{l}\text { Post-caudal/spinal } \\
\text { 5th min }\end{array}$ & $73.33 \pm 9.95$ & $79.29 \pm 19.22$ & $\mathrm{p}=0.201$ \\
\hline 10th min & $73.56 \pm 14.16$ & $78.88 \pm 16.72$ & $\mathrm{p}=0.283$ \\
\hline 15th min & $72.83 \pm 13.12$ & $78.04 \pm 17.00$ & $\mathrm{p}=0.287$ \\
\hline 30th min & $70.44 \pm 11.19$ & $77.92 \pm 16.77$ & $\mathrm{p}=0.110$ \\
\hline Post-surgery 1st min & $69.13 \pm 8.89$ & $75.55 \pm 18.32$ & $\mathrm{p}=0.179$ \\
\hline Postoperatif 15th min & $66.30 \pm 4.54$ & $74.21 \pm 14.44$ & $\mathrm{p}=0.072$ \\
\hline
\end{tabular}

Table 3

Modified Bromage scores of the study groups

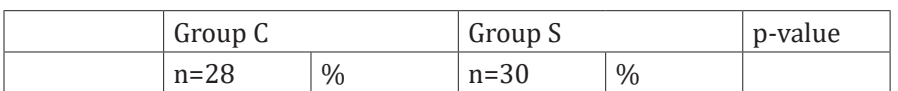

Post-caudal/spinal 5th min

\begin{tabular}{|l|l|l|l|l|l|}
\hline 0 & 28 & 100 & 6 & 20 & $\mathrm{p}=0.002^{*}$ \\
\hline 1 & 0 & 0 & 8 & 26.6 & \\
\hline 2 & 0 & 0 & 7 & 23.3 & \\
\hline 3 & 0 & 0 & 8 & 26.6 & \\
\hline
\end{tabular}

Post-caudal/spinal 10th min

\begin{tabular}{|l|l|l|l|l|l|}
\hline 0 & 28 & 100 & 4 & 13.3 & $\mathrm{p}=0.001^{*}$ \\
\hline 1 & 0 & 0 & 5 & 16.6 & \\
\hline 2 & 0 & 0 & 8 & 26.6 & \\
\hline 3 & 0 & 0 & 13 & 43.3 & \\
\hline
\end{tabular}

Post-caudal/spinal 15th min

\begin{tabular}{|l|l|l|l|l|l|}
\hline 0 & 28 & 100 & 3 & 10 & $\mathrm{p}=0.001^{*}$ \\
\hline 1 & 0 & 0 & 4 & 13.3 & \\
\hline 2 & 0 & 0 & 6 & 20 & \\
\hline 3 & 0 & 0 & 17 & 56.6 & \\
\hline
\end{tabular}

Post-caudal/spinal 30th min

\begin{tabular}{|l|l|l|l|l|l|}
\hline 0 & 28 & 100 & 3 & 10 & $\mathrm{p}=0.001^{*}$ \\
\hline 1 & 0 & 0 & 4 & 13.3 & \\
\hline 2 & 0 & 0 & 6 & 20 & \\
\hline 3 & 0 & 0 & 17 & 56.6 & \\
\hline
\end{tabular}

Completion of the surgery

\begin{tabular}{|l|l|l|l|l|l|}
\hline 0 & 28 & 100 & 3 & 10 & $\mathrm{p}=0.001^{*}$ \\
\hline 1 & 0 & 0 & 4 & 13.3 & \\
\hline 2 & 0 & 0 & 8 & 30 & \\
\hline 3 & 0 & 0 & 15 & 43.3 & \\
\hline
\end{tabular}

Postoperative 15 th $\min$.

\begin{tabular}{|l|l|l|l|l|l|}
\hline 0 & 28 & 0 & 3 & 10 & $\mathrm{p}=0.001^{*}$ \\
\hline 1 & 0 & 0 & 5 & 16.6 & \\
\hline 2 & 0 & 0 & 10 & 33.3 & \\
\hline 3 & 0 & 0 & 12 & 40 & \\
\hline
\end{tabular}

block was seen in the caudal epidural anesthesia group (Table 3). Maximum sensory blocks reached T6 dermatomes in spinal anesthesia group and T10 in caudal epidural group. Subjects randomized to spinal anesthesia also had a significantly more extensive sensorial block compared to those receiving caudal epidural anesthesia (Figure 1).
Figure 1 - Comparison of the groups with respect to the level of sensory block

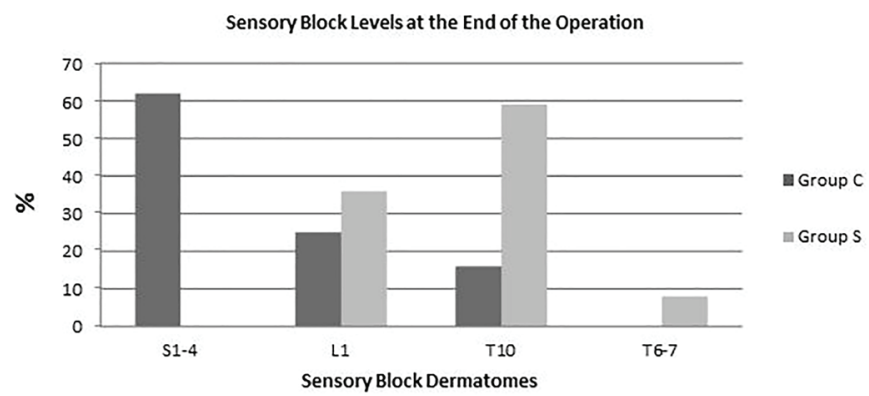

\begin{tabular}{|l|l|l|l|}
\multicolumn{1}{|c|}{ Table 4 } & \multicolumn{1}{c|}{$\begin{array}{l}\text { Postoperative visual analogue scale (VAS) } \\
\text { (Mean } \pm \text { SD) }\end{array}$} \\
\hline & Group C (n=28) & Group S (n=30) & $\mathrm{p}$-value \\
\hline $\begin{array}{l}\text { Postoperative } \\
\text { 15th min }\end{array}$ & $1.56 \pm 0.126$ & $1.78 \pm 0.18$ & $\mathrm{p}=0.084$ \\
\hline $\begin{array}{l}\text { Postoperative } \\
\text { 2nd hour }\end{array}$ & $2.35 \pm 0.24$ & $2.67 \pm 0.33$ & $\mathrm{p}=0.077$ \\
\hline $\begin{array}{l}\text { Postoperative } \\
\text { 12th hour }\end{array}$ & $3.46 \pm 0.41$ & $4.52 \pm 0.62$ & $\mathrm{p}=0.024^{*}$ \\
\hline $\begin{array}{l}\text { Postoperative } \\
\text { 24th hour }\end{array}$ & $0.5 \pm 0.06$ & $0.7 \pm 0.09$ & $\mathrm{p}=0.066$ \\
\hline
\end{tabular}

* p $<0.05$ Visuel Analog Scale in Group S was higher than Group C at postoperative 12 th hour

VAS score at postoperative 12 hours was significantly higher in subjects receiving spinal anesthesia (4.52 \pm 0.62$)$ compared to those receiving caudal epidural anesthesia $(3.46 \pm 0.41)(p=0.024)$ (Table 4). Time to first analgesic administration was significantly lower in subjects randomized to spinal anesthesia compared to those receiving caudal epidural anesthesia $(p=0.007)$. There were no significant differences between the groups with respect to the surgeons' or patients' satisfaction.

\section{Discussion}

This study showed that caudal epidural anesthesia would provide equal analgesia and les motor block compared to spinal anesthesia in subjects undergoing day-case perianal surgery. The findings in this study indicate that both caudal epidural anesthesia and spinal anesthesia provide similar hemodynamic profile in this patient population. Results of this study also reveal that spinal anesthesia provides more extensive motor and sensorial block compared to those receiving epidural anesthesia. However, postoperative pain is more prominent in subjects randomized to spinal anesthesia; thus, time to first analgesic requirement is shorter in this group of patients. However, both anesthetic techniques are associated with similar surgeon and patients' satisfaction.

Perianal surgical procedures are reported to account for up to $10 \%$ of general surgical procedures [21]. Perianal surgery is commonly performed on a day-case basis to reduce health-care costs and shorten unnecessary hospital stay. Consequently, central blocks are frequently utilized in the anesthetic management of subjects undergoing perianal surgery [22]. Regional anesthesia prevents spontaneous breathing and preventative reflexes remain active during the surgery; thus, recovery is rapid and patients can be mobilized in early postoperative period.

Spinal anesthesia with $0.5 \%$ isobaric bupivacaine or $2 \%$ lidocaine has long been used in anesthetic management of patients undergoing ambulatory anorectal surgery [23,24]. A single dose of isobaric bupivacaine has been reported to result in a block from L5 up to T2 level, which is actually 
unpredictable [25]. Hyperbaric spinal anesthesia can provide a more predictable block compared to isobaric spinal anesthesia $[23,26]$. However, hypotension and bradycardia, which may result in acute cardiovascular disorders, may occur in up to one-third of patients receiving spinal anesthesia [27]. Postdural puncture headache and transitory radicular irritation may also be encountered during spinal anesthesia, particularly with short-acting local anesthetic agents [28,29]. Hemodynamic side effects of spinal anesthesia has been overcome with the use of levobupivacaine, which has a wide margin between the therapeutic and toxic dose, lower cardiac toxicity compared to bupivacaine [30]. Therefore, levobupivacaine was preferred as a local anesthetic in our study. So, adequate anesthesia of the surgical area was provided with the use of levobupivacaine, and no hemodynamically significant side effects were observed in our study.

Caudal anesthesia is a simple and low-cost technique which has been safely used in perianal procedures [31]. Compared to spinal anesthesia, the level of motor block is more predictable with caudal epidural anesthesia [32]. Selective sensorial and motor block provided by caudal epidural anesthesia in the anorectal area without motor block in legs may facilitate early ambulation and discharge [33,34]. Temporary neurologic symptoms and postdural puncture headache, which seldom complicate spinal anesthesia, are rare with caudal epidural anesthesia [35-37]. Moreover, the incidence of hypotension and bradycardia is much lower with caudal epidural anesthesia compared to spinal anesthesia. However, several anatomical variations including upward and downward displacement of the hiatus, pronounced narrowing or partial obliteration of the sacral canal, and ossification of the sacrococcygeal membrane may complicate needle insertion and lead to a failure in performing caudal epidural anesthesia [25]. Nevertheless, the rate of failure is extremely low when the procedure is performed by experienced anesthetists [38]. In this study, caudal blocks were performed by experienced people using traditional methods. Adequate anesthesia level was achieved with this block. No clinically significant complications were encountered.

Both spinal anesthesia and caudal epidural anesthesia are commonly used for the anesthetic management of patients undergoing perianal surgery. However, there is limited research comparing the two techniques in terms of the adequacy of the sensory and motor block, hemodynamic changes, postoperative pain and surgeons' and patients' satisfaction. We hypothesized that caudal epidural anesthesia would provide less motor and sensory block and better intraoperative hemodynamics compared to spinal anesthesia. Our findings show that spinal anesthesia is associated with more extensive motor and sensory block compared to caudal epidural anesthesia. Moreover, no significant differences occurred in MAP and heart rate between spinal and caudal anesthesia. This may particularly explained by the use of levobupivacaine for spinal anesthesia, which has reduced cardiovascular toxicity compared to tradition local anesthetic agents such as bupivacain. We also found out that, VAS score indicating postperative pain at $12^{\text {th }}$ hour was significantly higher in subjects receiving spinal anesthesia compared to those receiving caudal block. Although the sensorial block provided by spinal anesthesia is more extensive compared to caudal block, it appears that durability of the sensory block is shorter with spinal aneshteisa than caudal block. However, the difference in surgical pain at postoperative $12^{\text {th }}$ hour did not translate into patients' satisfaction. This may be associated with the limited number of patients enrolled in the study. Further studies with larger sample size are required to clearly address the effect of caudal block on patients' satisfaction in perianal surgery.

Given that caudal epidural anesthesia provides less extensive motor block compared to spinal anesthesia, patients undergoing day-case perianal surgery with caudal block may be ambulated early in the postoperative period and discharged without delay.

There are some limitations concerning the present study. The sample size is relatively small. Data concerning the time to ambulation and time to urination are lacking. Strict criteria were not used for the discharge of patients in our hospital. Therefore, we cannot clearly state that caudal block has advantages over spinal anesthesia regarding early ambulation and urinary retention. However, limited motor block to anorectal area in our study population makes us speculate that caudal block may facilitate ambulation in subjects undergoing perianal surgery.

\section{Conclusion}

Spinal anesthesia is associated with more extensive sensory and motor block compared to caudal epidural anesthesia in patients undergoing perianal surgery. Both techniques lead to similar hemodynamic changes. Postoperative pain control is more favorable with caudal block than the spinal anesthesia. However, neither surgeons nor the patients' satisfaction is different between the two techniques. Lack of motor block with caudal epidural anesthesia may facilitate ambulation and discharger in patients undergoing day-case perianal surgery.

\section{Highlights of the Study}

- Advances in anesthetic and surgical techniques led to an increase in outpatient surgical procedures.

- Performing several surgeries in outpatient setting not only reduces healthcare costs but also increases patients' satisfaction due to same day discharge after the procedure

- General anesthesia, local anesthesia, and regional anesthesia techniques have traditionally been used in anesthesia management of patients undergoing perianal surgery

Disclosures: There is no conflict of interest for all authors.

\section{Acknowledgements: None.}

\section{Funding: None.}

Author contributions: Akdogan Ali was involved in the study concept and design, primary data verification, responsible for the accuracy of the statistical analyses, and critical revision of the manuscript's intellectual content. Bozkurt Cigdem was involved in primary data collection and verification and data analysis and interpretation. Erturk E was involved in the study concept and design, primary data collection, analysis and data interpretation, manuscript drafting, and critical revision of the manuscript's intellectual content. Kesicioglu Tugrul was involved in primary data collection and verification and data analysis and interpretation. Aydin Ismail was involved in primary data collection and verification and data analysis and interpretation. 


\section{References}

1. Ojo EO. Day case surgery and developing countries: a review. Niger J Clin Pract. 2010; 13(4):459-66. PMID: 21220866.

2. Alley EA, Mulory MF. Neuraxial anesthesia for outpatients. Anesthesiol Clin. 2014; 32(2):357-69. doi: 10.1016/j.anclin.2014.02.007. PMID: 24882123.

3. Gabriel RA, Ilfeld BM. Use of Regional Anesthesia for Outpatient Surgery Within the United States: A Prevalence Study Using a Nationwide Database. Anesth Analg. 2018; 126(6):2078-2084. doi: 10.1213/ANE.0000000000002503. PMID: 28922231.

4. Li J, Lam D, King H, Credaroli E, Harmon E, Vadivelu N. Novel Regional Anesthesia for Outpatient Surgery. Curr Pain Headache Rep. 2019; 23(10):69. doi: 10.1007/s11916-019-0809-6. PMID: 31372836.

5. Mulroy MF, McDonald SB. Regional anesthesia for outpatient surgery. Anesthesiol Clin North Am. 2003; 21(2):289-303. doi: 10.1016/ s0889-8537(02)00071-8. PMID: 12812396.

6. Gebhardt V, Kiefer K, Bussen D, Weiss C, Schmittner MD. Retrospective analysis of mepivacaine, prilocaine and chloroprocaine for low-dose spinal anaesthesia in outpatient perianal procedures. Int J Colorectal Dis. 2018; 33(10):1469-1477. doi: 10.1007/s00384-0183085-8. Epub 2018 May 13. PMID: 29756162.

7. Jamshidi R. Anorectal Complaints: Hemorrhoids, Fissures, Abscesses, Fistulae. Clin Colon Rectal Surg. 2018; 31(2):117-120. doi: 1055/s-0037-1609026. Epub 2018 Feb 25. PMID: 29487494; PMCID: PMC5825861.

8. Gerjy R, Lindhoff-Larson A, Sjödahl R, Nyström PO. Randomized clinical trial of stapled haemorrhoidopexy performed under local perianal block versus general anaesthesia. Br J Surg. 2008; 95(11):1344-51. doi: 10.1002/bjs.6379. PMID: 18844245.

9. Stokes R, Wanaguru D, Saadi A, Adams S. Management of perianal abscesses in infants without general anaesthesia: a systematic review of the literature. Pediatr Surg Int. 2020; 36(11):1317-1325. doi: 10.1007/s00383-020-04728-7. Epub 2020 Aug 12. PMID: 32785778.

10. Bussen D, Sailer M, Fuchs KH, Thiede A. Tumeszenz-Lokalanästhesie bei proktologischen Eingriffen [Tumescent local anesthesia in proctologic surgery]. Chirurg. 2003; 74(9):839-43. German. doi: 10.1007/s00104-003-0670-2. PMID: 14504797.

11. Falco N, Tutino R, Fontana T, Gullo R, Licari L, Raspanti C et al. Outpatient management of proctologic disease. Which techniques for local anesthesia? The experience of a single center. G Chir. 2019; 40(3):182-187. PMID: 31484006.

12. Gerjy R, Derwinger K, Nyström PO. Perianal local block for stapled anopexy. Dis Colon Rectum. 2006; 49(12):1914-21. doi: 10.1007/ s10350-006-0750-8. PMID: 17080277.

13. Boublik J, Gupta R, Bhar S, Atchabahian A. Prilocaine spinal anesthesia for ambulatory surgery: A review of the available studies. Anaesth Crit Care Pain Med. 2016; 35(6):417-421. doi: 10.1016/j.accpm.2016.03.005. Epub 2016 Jun 21. PMID: 27352633.

14. Wassef MR, Michaels EI, Rangel JM, Tsyrlin AT. Spinal perianal block: a prospective, randomized, double-blind comparison with spinal saddle block. Anesth Analg. 2007; 104(6):1594-6, table of contents. doi: 10.1213/01.ane.0000261510.37489.00. PMID: 17513664.

15. Chan VW, Garcia J, Al-Kaisy A, Drasner K. A comparative study of low-dose hyperbaric spinal lidocaine $0.5 \%$ versus $5 \%$ for continuous spinal anesthesia. Reg Anesth Pain Med. 1998; 23(2):164-9. doi: 10.1097/00115550-199823020-00009. PMID: 9570605.

16. Kazak Z, Ekmekci P, Kazbek K. Hyperbaric levobupivacaine in anal surgery : Spinal perianal and spinal saddle blocks. Anaesthesist. 2010; 59(8):709-13. doi: 10.1007/s00101-010-1755-1. Epub 2010 Jul 30. PMID: 20668826.

17. Schmittner MD, Schreiber H, Janke A, Weiss C, Blunk J, Bussen DG, Luecke T. Randomized clinical trial of perianal surgery performed under spinal saddle block versus total intravenous anaesthesia. Br J Surg. 2010; 97(1):12-20. doi: 10.1002/bjs.6792. PMID: 19937984.

18. LEWIS MS, AUSTIN RB. Continuous caudal versus saddle-block anesthesia in obstetrics. Am J Obstet Gynecol. 1950; 59(5):1146-52. doi: 10.1016/s0002-9378(16)39184-0. PMID: 15410836.

19. Satoh M, Hasebe K, Tsujimoto Y, Takada T, Honda M, Fujioka H. [Examination of the anesthesia on transperineal prostate biopsy-saddle block versus caudal block]. Hinyokika Kiyo. 2005; 51(7):443-5. Japanese. PMID: 16119806.

20. Seyedhejazi M, Moghadam A, Sharabiani BA, Golzari SE, Taghizadieh N. Success rates and complications of awake caudal versus spinal block in preterm infants undergoing inguinal hernia repair: A prospective study. Saudi J Anaesth. 2015; 9(4):348-52. doi: 10.4103/1658-354X.154704. PMID: 26543447; PMCID: PMC4610074.

21. Kaban OG, Yazicioglu D, Akkaya T, Sayin MM, Seker D, Gumus H. Spinal anaesthesia with hyperbaric prilocaine in day-case perianal surgery: randomised controlled trial. ScientificWorldJournal. 2014; 2014:608372. doi: 10.1155/2014/608372. Epub 2014 Oct 14. PMID: 25379541; PMCID: PMC4214037.

22. Watson B, Howell V. Spinal anaesthesia: the saviour of day surgery? Current Anaesthesia \& Critical Care. 2007; 18:193-199. DOI: 10.1016/j.cacc.2007.07.004

23. Gudaityte J, Marchertiene I, Karbonskiene A, Saladzinskas Z, Tamelis A, Toker I, Pavalkis D. Low-dose spinal hyperbaric bupivacaine for adult anorectal surgery: a double-blinded, randomized, controlled study. J Clin Anesth. 2009; 21(7):474-81. doi: 10.1016/j. jclinane.2008.11.014. PMID: 20006254.

24. Imbelloni LE, Gouveia MA, Cordeiro JA. Hypobaric $0.15 \%$ bupivacaine versus hypobaric $0.6 \%$ lidocaine for posterior spinal anesthesia in outpatient anorectal surgery. Rev Bras Anestesiol. 2010; 60(2):113-20, 64-8. English, Portuguese, Spanish. doi: 10.1016/s00347094(10)70015-5. PMID: 20485955.

25. Gudaityte J, Marchertiene I, Pavalkis D. Anesthesia for ambulatory anorectal surgery. Medicina (Kaunas). 2004; 40(2):101-11. English, Lithuanian. PMID: 15007268.

26. Gudaityte J, Marchertiene I, Pavalkis D, Saladzinskas Z, Tamelis A, Tokeris I. Spinalinio hiperbarinio bupivakaino minimali veiksminga doze darant anorektalines operacijas (dvigubai aklas atsitiktiniu imciu tyrimas) [Minimal effective dose of spinal hyperbaric bupivacaine for adult anorectal surgery: a double-blind, randomized study]. Medicina (Kaunas). 2005; 41(8):675-84. Lithuanian. PMID: 16160416.

27. Liu SS, McDonald SB. Current issues in spinal anesthesia. Anesthesiology. 2001; 94(5):888-906. doi: 10.1097/00000542-20010500000030. PMID: 11388543.

28. Hampl KF, Schneider MC, Ummenhofer W, Drewe J. Transient neurologic symptoms after spinal anesthesia. Anesth Analg. 1995; 81(6):1148-53. doi: 10.1097/00000539-199512000-00006. PMID: 7486096.

29. Dahlgren N. Lidocaine toxicity: a technical knock-out below the waist? Acta Anaesthesiol Scand. 1998; 42(4):389-90. doi: 10.1111/ j.1399-6576.1998.tb05130.x. PMID: 9563855. 
30. Alley EA, Kopacz DJ, McDonald SB, Liu SS. Hyperbaric spinal levobupivacaine: a comparison to racemic bupivacaine in volunteers. Anesth Analg. 2002; 94(1):188-93, table of contents. doi: 10.1097/00000539-200201000-00036. PMID: 11772826.

31. Adebamowo CA, Ladipo JK, Ajao OG. Randomized comparison of agents for caudal anaesthesia in anal surgery. Br J Surg. 1996; 83(3):364-5. doi: 10.1002/bjs.1800830321. PMID: 8665193.

32. Chan MT, Lam KK. Randomized comparison of agents for caudal anaesthesia in anal surgery. Br J Surg. 1996; 83(9):1300. PMID: 8983632. https://doi.org/10.1046/j.1365-2168.1996.00063.x

33. Wang N, Fu Y, Ma H, Wang J, Gao Y. Advantages of caudal block over intrarectal local anesthesia plus periprostatic nerve block for transrectal ultrasound guided prostate biopsy. Pak J Med Sci. 2016; 32(4):978-982. doi:10.12669/pjms.324.9823

34. Villalobos MA, Veneziano G, Miller R, Beltran RJ, Krishna S, Tumin D et al. Evaluation of postoperative analgesia in pediatric patients after hip surgery: lumbar plexus versus caudal epidural analgesia. J Pain Res. 2019; 12:997-1001. doi: 10.2147/JPR.S191945. PMID: 31118744; PMCID: PMC6498965.

35. Dawkins CJ. An analysis of the complications of extradural and caudal block. Anaesthesia. 1969; 24(4):554-63. doi: 10.1111/j.13652044.1969.tb02909.x. PMID: 4242599.

36. Kao SC, Lin CS. Caudal Epidural Block: An Updated Review of Anatomy and Techniques. Biomed Res Int. 2017; 2017:9217145. doi: 10.1155/2017/9217145. Epub 2017 Feb 26. PMID: 28337460 ; PMCID: PMC5346404.

37. Wiegele M, Marhofer P, Lönnqvist PA. Caudal epidural blocks in paediatric patients: a review and practical considerations. Br J Anaesth. 2019; 122(4):509-517. doi: 10.1016/j.bja.2018.11.030. Epub 2019 Feb 1. PMID: 30857607; PMCID: PMC6435837.

38. Tetzlaff JE. Cousins and Bridenbaugh's Neural Blockade in Clinical Anesthesia and Pain Medicine. Mayo Clin Proc. $2010 ; 85(7)$ :e51. doi: 10.4065/mcp.2010.0230. PMCID: PMC2894732. 